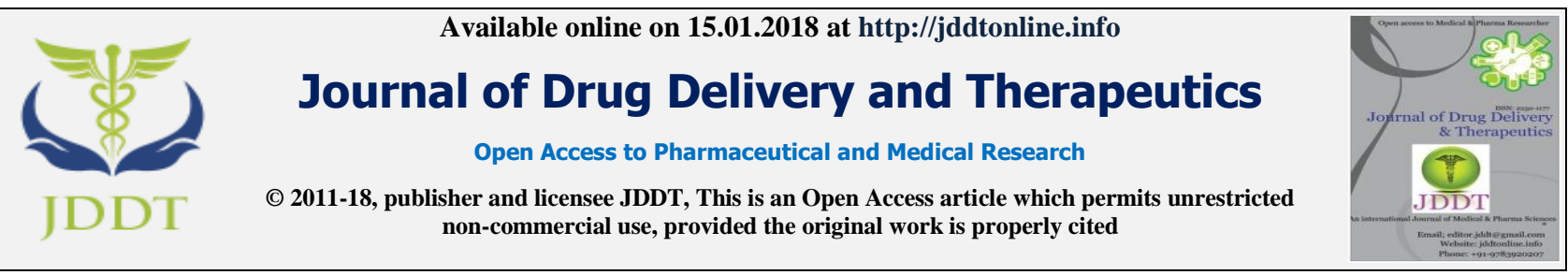

Open $\odot$ Access

Re search Article

\title{
CRYSTAL ENGINEERING OF ANTIVIRAL AGENT EFAVIRENZ FOR SOLUBILITY ENHANCEMENT
}

\author{
Gadade Dipak D.*1, Pekamwar Sanjay S. ${ }^{1}$, Shirsat Mahendra D ${ }^{2}$ \\ ${ }^{1}$ School of Pharmacy, S.R.T.M. University, Vishnupuri, Nanded (India) - 431606 \\ ${ }^{2}$ RUSA Centre for Advanced Sensor Technology University Campus, Aurangabad (India) - 431004
}

\begin{abstract}
In the current study, we attempted to improve the physicochemical properties of antiviral drug efavirenz through the cocrystal synthesis. The neat grinding performed to study the effect of coformer-fumaric acid (FA) on solubility and dissolution of efavirenz, which can serve as the green cocrystal synthesis approach. The prepared cocrystals were characterized for characteristics like powder flow properties, aqueous saturation solubility, in vitro powder dissolution study. The synthesized cocrystals were characterized by Fourier transform infrared spectroscopy, differential scanning calorimetry, powder X-ray diffraction. The formation of a cocrystal of efavirenz and caffeine was confirmed by the characterization techniques which suggests the interactions between efavirenz and coformer-fumaric acid leads to cocrystal formation. The powder flow properties, solubility, and dissolution profile of efavirenz are significantly improved by its cocrystallization.
\end{abstract}

Keywords: Efavirenz; cocrystal; solubility; dissolution; crystal engineering.

Article Info: Received 23 Dec, 2017; Review Completed 10 Jan, 2018; Accepted 13 Jan, 2018; Available online 15 Jan, 2018

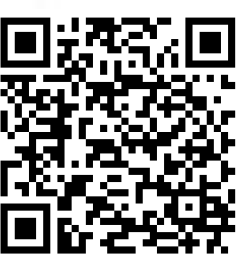

Cite this article as:

Gadade DD, Pekamwar SS, Shirsat MD, Crystal engineering of antiviral agent efavirenz for solubility enhancement, Journal of Drug Delivery and Therapeutics. 2018; 8(1):86-91

DOI: http://dx.doi.org/10.22270/jddt.v8i1.1637

*Address for Correspondence

Gadade Dipak D, School of Pharmacy, S.R.T.M. University, Vishnupuri, Nanded (India) - 431606. Email: deeps_cpn@yahoo.co.in, Contact-+918275516317

\section{INTRODUCTION}

Crystal engineering or solid state supramolecular synthesis deals with the understanding of intermolecular interactions in the context of crystal packing and in applying this understanding to the design of pre-desired crystal structures with specific physical or chemical properties ${ }^{1}$.' Co-crystals are solids that are crystalline materials composed of two or more molecules in the same crystal lattice. Given the association of two or more molecules in the co-crystal lattice, it is useful to consider the association of components more generally 2 .

Neat grinding method without utilizing any solvents 3,4 or by solvent drop grinding 5 , where the small or acceptable amount of solvent is utilized which ultimately evaporate during synthetic process ${ }^{6,7}$ can be used to cocrystals green synthesis method. It is outcome of non-covalent interactions which include hydrogen bonding, dipole interactions, $\pi-\pi$ interactions, ion- $\pi$ interactions, halogen bonding, closed shell interactions or van der Waals interactions. The selection of the second component in cocrystal synthesis i.e. coformer is crucial in the development of multicomponent systems. The properties of coformers decide the fate of cocrystal system; it has implications on physicochemical properties as well as the pharmacokinetic behaviour of cocrystals ${ }^{8}$.

Efavirenz, (4S)-6-chloro-4- (cyclopropylethynyl)-4(trifluoromethyl)-1,4-dihydro-2H-3,1-benzoxazine-2one, is a HIV-1 specific, non-nucleoside reverse transcriptase inhibitor ${ }^{9}$. It was approved for the treatment of human immunodeficiency virus type-1 infection (HIV-1). Efavirenz (EFV) belongs to Biopharmaceutical Classification System (BCS) class II. 
Being poorly water soluble drug, significant differences in bioavailability can be observed in the various polymorphic forms of EFV ${ }^{10}$. Previous studies reported attempts to improve solubility and dissolution of EFV by solid dispersion and drug milling ${ }^{11,12}$. It was also revealed that EFV shows improved pharmaceutical properties by cocrystallization with adipic acid ${ }^{13}$, lactic acid $^{14}$, glutaric acid ${ }^{15}$.

In this work we attempted to prepare cocrystals of EFV with fumaric acid (FA) for enhancement of pharmaceutically physicochemical properties of EFV, and to characterize the cocrystals using powder Fourier transform infrared (FTIR), differential scanning calorimetry (DSC), powder X-ray powder diffraction (PXRD), saturation solubility and dissolutions.

\section{MATERIAL AND METHODS}

EFV was obtained as gift sample from Mylan Laboratories, Hyderabad. FA was procured from Research Fine Lab, Mumbai. All other chemicals and solvents employed in present work were of analytical grade and procured from Research Fine Lab, Mumbai.

\subsection{Miscibility of the components}

Hansen solubility parameters of EFV and FA were computed by using the group contribution method following the collective utilization models of Fedors and Van Krevelen-Hoftyzer. The solubility parameter components were computed from group contributions (F) and molar volume ( $\mathrm{Vm})$, using the following equations where $\delta \mathrm{d}$ represent dispersion forces energy, $\delta \mathrm{p}$ represents polar forces energy and $\delta \mathrm{h}$ represents hydrogen bonding energy ${ }^{16,17}$.

$$
\begin{aligned}
& \delta \mathrm{d}=\left(\sum \mathrm{Fdi} / \sum \mathrm{Vm}\right) \\
& \delta \mathrm{p}=\left(\left[\sum \mathrm{Fpi}\right]^{0.5} / \sum \mathrm{Vm}\right) \\
& \delta \mathrm{h}=\left(\sum \mathrm{Fhi} / \sum \mathrm{Vm}\right)^{0.5} \\
& \delta \mathrm{t}=\left(\delta^{2} \mathrm{~d}+\delta^{2} \mathrm{p}+\delta^{2} \mathrm{~h}\right)^{0.5}
\end{aligned}
$$

Miscibility of components can be predicted according to predictive principle that if $\Delta \delta \mathrm{t}<7 \mathrm{MPa}^{0.5}$ of the components they may be miscible and forms multicomponent system and hence, if this criterion is fulfilled the cocrystal may be formed.

\subsection{Preparation of cocrystals}

Cocrystals of EFV with coformers were prepared by the neat grinding method. A stoichiometric mixture of EFV and coformer-FA $(1: 1 \mathrm{M})$ was ground in an agate mortar with a pestle for about 20 mins by neat grinding method (NG). The obtained cocrystals were used for characterization ${ }^{18}$.

\subsection{Micromeritic properties}

The active pharmaceutical ingredient-EFV and its corystals with FA was evaluated for various micromeritic flow properties that is bulk density, tapped density, Carr's index, Hausner's ratio and angle of repose $^{19}$.

\subsection{ATR-Fourier transform infrared spectroscopy (FTIR)}

Fourier transform infrared spectroscopy (FTIR) was employed for the vibrational spectroscopic analysis of the active pharmaceutical ingredient (API)-EFV and its cocrystals with a coformer-FA obtained by NG method 18. The FTIR spectrums were recorded with the FTIR spectrophotometer with ATR attachment (Bruker; ALPHA-T) and the scanning range was in between $4000-660 \mathrm{~cm}^{-1}$.

\subsection{Thermal Analysis}

Differential scanning calorimetry (DSC) studies were performed using Shimadzu TA-60WS Module to understand the thermal characteristics of an EFV alone and its cocrystal with FA. Weighed samples were heated in aluminum pans at a rate of $20^{\circ} \mathrm{C} / \mathrm{min}$, from 50 to $300^{\circ} \mathrm{C}$ temperature range, under a nitrogen atmosphere and empty aluminum pan were used as a reference ${ }^{20,21}$.

\subsection{Powder X-ray diffraction (PXRD)}

PXRD patterns were obtained using a Bruker D8 Advance X-ray diffractometer ( $\mathrm{Cu} \mathrm{K} \alpha$ radiation). A continuous scanning method was used for recording with a fixed tube current $(32 \mathrm{~mA})$ and a $40 \mathrm{kV}$ voltage. The scanning range of $5-50^{\circ}(2 \theta)$ was used to measure the diffraction intensities of powder samples of API and cocrystals $^{22}$.

\subsection{Saturation Solubility Study}

Solubility studies EFV and its cocrystal with FA was performed in accordance method reported by Higuchi and Connors ${ }^{23}$. For saturation solubility, an excess quantity of cocrystal powder was added to distilled water. The vials were then subjected to rotary shaking for 24 hours and filtrate obtained after filtration through the $0.2 \mu \mathrm{m}$ pore size membrane filter $\left(\right.$ Whatman $^{\circledR}$ ) was analyzed by UV spectrophotometer at $247.6 \mathrm{~nm}$.

\subsection{Powder Dissolution Study and Intrinsic dissolution rate study (IDR)}

Powder dissolution study of EFV and its cocrystal with FA was performed using $2 \%$ aqueous sodilum lauryl sulphate as dissolution medium at $37 \pm 0.5^{\circ} \mathrm{C}$. An aliquot of dissolution medium was withdrawn at 10, 15, 30, 45, and $60 \mathrm{~min}$ intervals and concentration of API was determined at $247.6 \mathrm{~nm}$ spectro-photometrically.

The intrinsic dissolution rate of EFV and EFV-FA cocrystals was evaluated to study dissolution of API per unit area and time. The tablets of EFV and EFV-FA cocrystals with hardness $8 \mathrm{~kg} / \mathrm{cm}^{2}$ were compressed. The tablet compacts were coated using paraffin wax, leaving only the surface under investigation free for dissolution and affixed to the paddle of USP dissolution apparatus. The IDR studies were performed in $2 \%$ SLS at $37^{\circ} \mathrm{C}$ for 120 mins. The intrinsic dissolution rate (IDR) was determined from the slope of the dissolution time profiles ${ }^{24}$. 


\section{RESULTS AND DISCUSSION}

\subsection{Miscibility of the components}

Solubility parameters $(\delta \mathrm{t})$ for $\mathrm{EFV}$ and FA were computed using the group contribution method following the collective utilization models of Fedors and Van Krevelen-Hoftyzer and reported in the table 1.

Table 1: Solubility parameters (HSP) for EFV and FA

\begin{tabular}{|l|l|l|l|l|}
\hline Particulars & $\boldsymbol{\delta} \mathbf{d}^{*}$ & $\boldsymbol{\delta} \mathbf{p}^{*}$ & $\boldsymbol{\delta} \mathbf{h}^{*}$ & $\boldsymbol{\delta} \mathbf{t}^{*}$ \\
\hline EFV & 28.56 & 7.16 & 7.55 & 30.40 \\
\hline FA & 17.38 & 7.07 & 15.43 & 24.29 \\
\hline \multicolumn{5}{|c}{$*\left(\mathrm{MJ} / \mathrm{m}^{3}\right)^{1 / 2}$}
\end{tabular}

The resulting $\Delta \delta$ value for $\mathrm{EFV}$ and $\mathrm{FA}$ is 6.11 $\left(\mathrm{MJ} / \mathrm{m}^{3}\right)^{1 / 2}$ which indicates the miscibility of an API with the coformer-FA ${ }^{16)}$ as $\Delta \delta$ value $<7$. It indicates that the components are miscible consequently may result in formation of cocrystal ${ }^{19,25}$.

\subsection{Micromeritic properties}

Carr's index and Hausner's ratio were derived from bulk density and tapped density of materials (Table 2). Carr's Index and Hausner's ratio for unprocessed EFV were fits into passable scale while these properties for EFVFA cocrystal can be scaled into good to fair flow property on the scale of flowability ${ }^{26}$. It shows improved flow properties of later against unprocessed EFV.

Table 1: Micromeritic properties of EFV and its cocrystal

\begin{tabular}{|l|l|l|l|l|l|}
\hline Material & Bulk Density $\left(\mathrm{g} / \mathrm{cm}^{3}\right)$ & Tapped density $\left(\mathrm{g} / \mathrm{cm}^{3}\right)$ & Carr's Index & Hausner Ratio & Angle of repose \\
\hline EFV* & $0.2535 \pm 0.0015$ & $0.3288 \pm 0.0045$ & $22.89 \pm 1.15 \%$ & $1.30 \pm 0.019$ & $43.99^{\circ} \pm 2.39^{\circ}$ \\
\hline Cocrystal $^{*}$ & $0.3521 \pm 0.0049$ & $0.4145 \pm 0.0104$ & $17.93 \pm 0.99 \%$ & $1.17 \pm 0.013$ & $36.94^{\circ} \pm 1.66^{\circ}$ \\
\hline
\end{tabular}
$*(n=3)$

\subsection{Vibrational spectroscopic study}

The assignments to the major vibrational peaks in the FTIR spectral studies ${ }^{27}$ (Fig.1) were as elucidated in table 3. The additional new peaks were observed in spectrum of EFV-FA cocrystal at $1681.48 \mathrm{~cm}^{-1}$ and $3742.82 \mathrm{~cm}^{-1}$ which can assigned to aliphatic alkene and hydroxyl functions in the fumaric acid respectively. The peak of tri-fluoro-alkane function in the EFV was shifted from $1325.00 \mathrm{~cm}^{-1}$ to $1317.52 \mathrm{~cm}^{-1}$ suggesting its participation in intermolecular interactions. These peaks may be assigned to halogen bonding interaction between fluorine functions of EFV with cyclic amine function of FA due to cocrystal formation. The additional peaks observed are marked in sprectrum which suggests the formation cocrystal.
Table 2: Assignment of vibrational frequencies to EFV and its cocrystal

\begin{tabular}{|c|c|c|c|}
\hline \multicolumn{2}{|c|}{ EFV $\left(\mathbf{c m}^{-\mathbf{1}}\right)$} & \multicolumn{2}{c|}{ EFV FA Cocrystal $\left(\mathbf{c m}^{-\mathbf{1}}\right)$} \\
\hline Group & FTIR & Group & FTIR \\
\hline $\mathrm{NH}$ & 3311.97, & $\mathrm{NH}$ & 3312.23, \\
& 806.95 & & 807.32 \\
\hline $\mathrm{CH}$ & 1495.28 & $\mathrm{CH} 3$ & 3087.72 \\
\hline Alkyne & 2247.52 & Alkyne & 2247.62 \\
\hline $\mathrm{C}=\mathrm{O}$ & 1745.67 & $\mathrm{C}=\mathrm{O}$ & 1746.49 \\
\hline$-\mathrm{Ar}-\mathrm{C}=\mathrm{C}$ & 1601.35 & $-\mathrm{Ar}-\mathrm{C}=\mathrm{C}$ & 1601.82 \\
& & $\mathrm{C}=\mathrm{C}$ & $\mathbf{1 6 8 1 . 4 8}$ \\
\hline$-\mathrm{CF} 3$ & 1325.00 & $-\mathrm{CF} 3$ & $\mathbf{1 3 1 7 . 5 2}$ \\
\hline$-\mathrm{C}-\mathrm{O}-\mathrm{C}$ & 1188.50 & $-\mathrm{C}-\mathrm{O}-\mathrm{C}$ & 1188.15 \\
\hline$-\mathrm{C}-\mathrm{Cl}$ & 1074.87 & $-\mathrm{C}-\mathrm{Cl}$ & 1074.33 \\
\hline$-\mathrm{OH}$ & -- & $-\mathrm{OH}$ & $\mathbf{3 7 4 2 . 8 2}$ \\
\hline
\end{tabular}

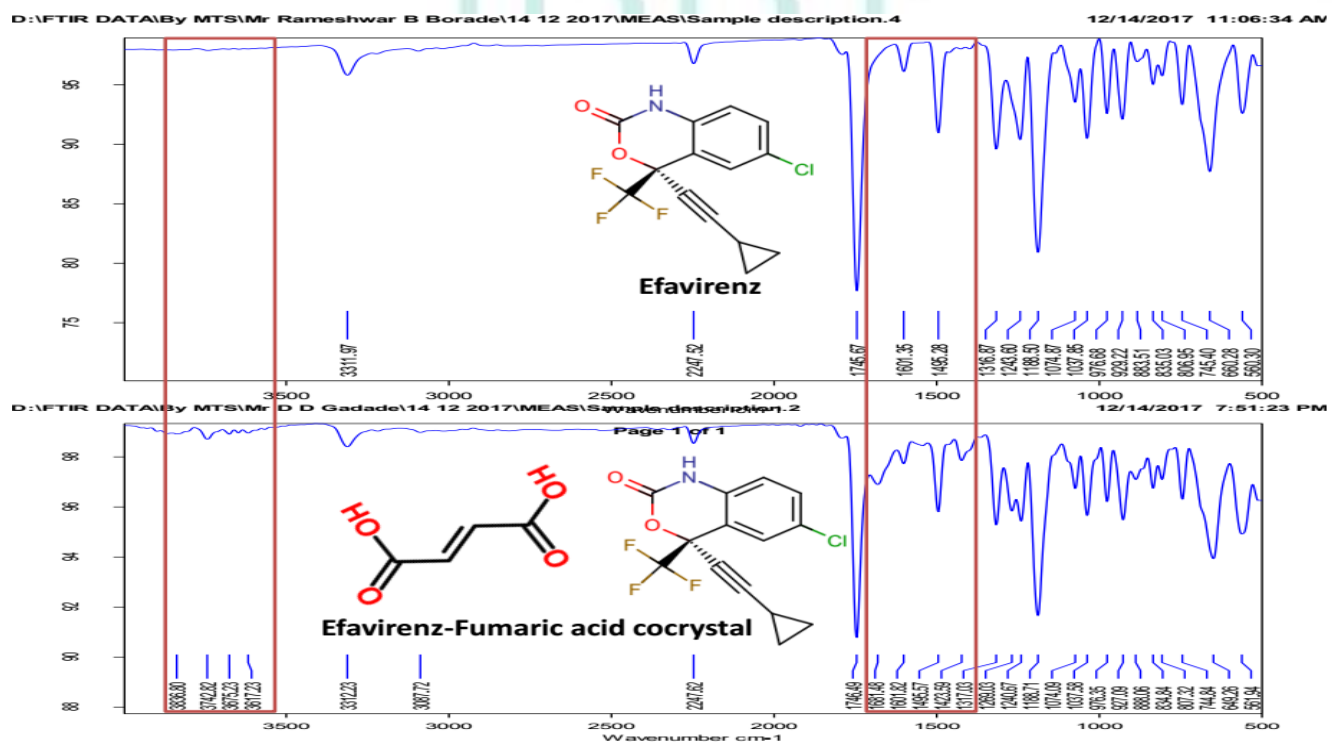

Figure 1 FTIR spectra of EFV and EFV-FA cocrystal 


\subsection{Thermal Analysis}

EFV shows melting at $140.15{ }^{\circ} \mathrm{C}$ with heat $48.61 \mathrm{~J} / \mathrm{g}$ which was confirmed to be its form I from reported literature ${ }^{9,10}$ EFV-FA cocrystal shows melting at 208.76
${ }^{\circ} \mathrm{C}$ and an additional peak at $266.76^{\circ} \mathrm{C}$ were observed in DSC thermogram (Fig. 2). It indicates formation of new phase which altered melting behaviour and which supports to assumption of EFV-FA cocrystal formation.

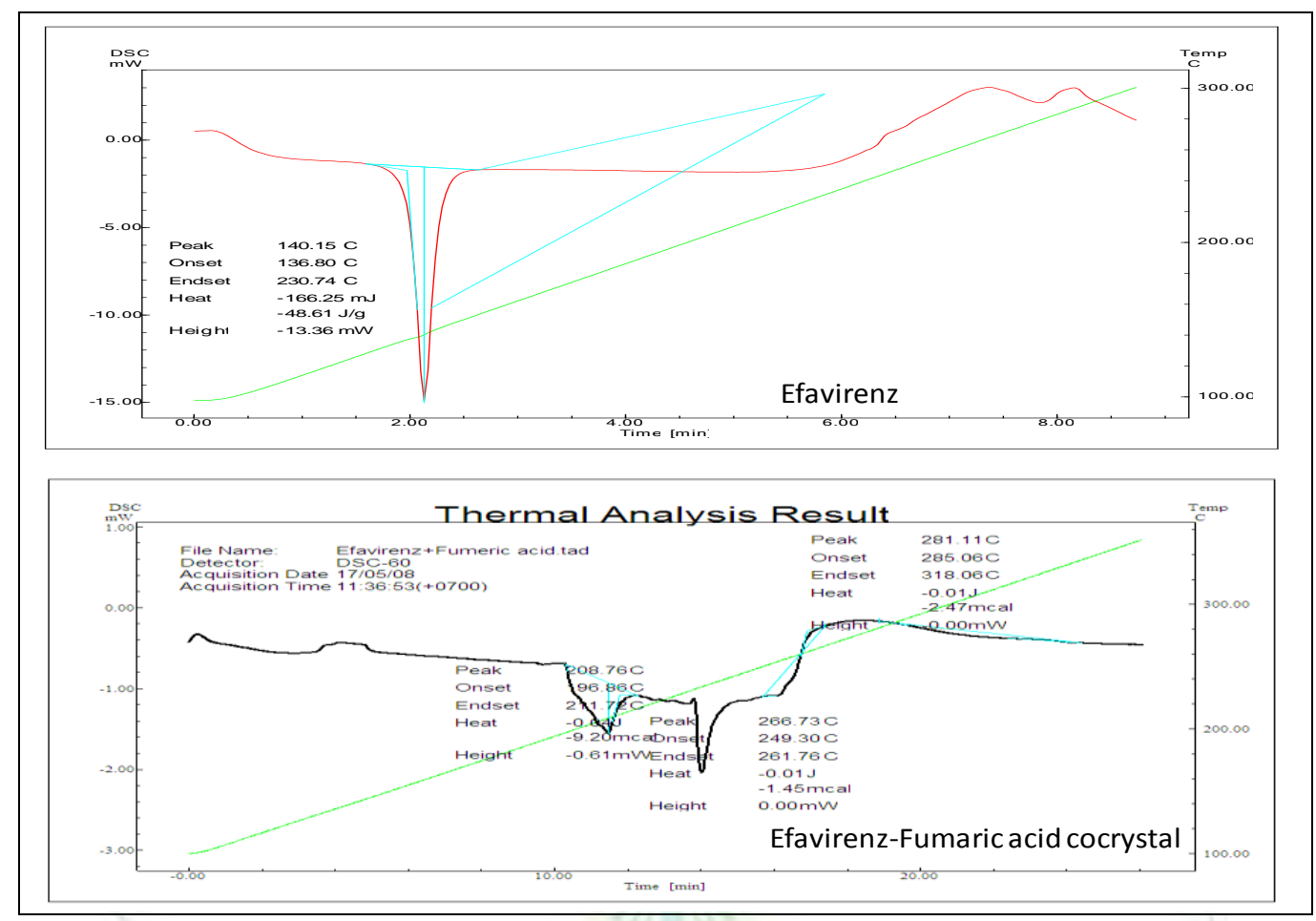

Figure 2 DSC thermogram of EFV and EFV-FA cocrystal

\subsection{Powder X-ray diffraction (PXRD)}

PXRD study was employed to assess transformations in the crystallographic nature of an API and coformer subsequent to the cocrystallization (Fig. 3). In correlation with the reported data $^{28}$ for EFV, a very intense peak was observed around $2 \theta$ of 6.26 along with $10.80,11.26,12.1,13.6,14.54,15.56,17.1,19.18,20.3$,
21.4 and 25.04. In contrast to PXRD pattern of EFV, additional characteristic distinct multiple sharp peaks were observed at $2 \theta$ of $28.79,29.41,38.62$ in the diffractogram of cocrystal which can be assigned to the formation of new crystalline phases in cocrystal of EFV$\mathrm{FA}^{29}$.

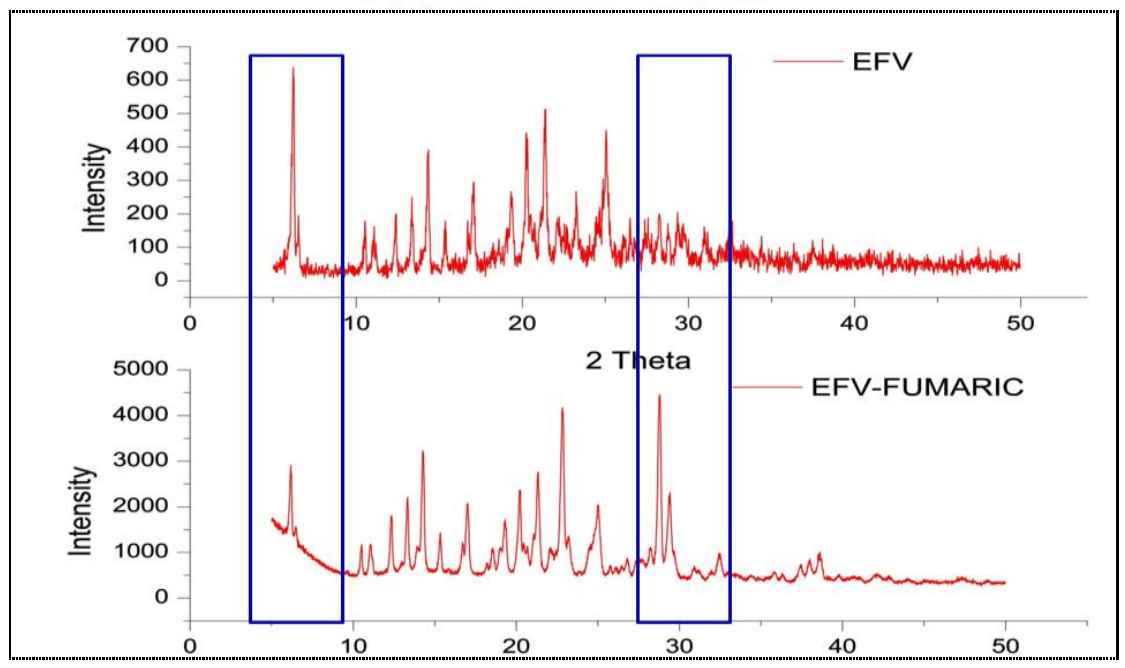

Figure 3 PXRD diffractograms of EFV, FA and their cocrystal 


\subsection{Saturation Solubility Study}

Saturated solubility of EFV was found to be 8.39 $( \pm 0.10) \mu \mathrm{g} / \mathrm{ml}$ in distilled water and it was improved in cocrystal form with FA to $223.6( \pm 11.88) \mu \mathrm{g} / \mathrm{ml}$. It clearly indicates solubility advantage of cocrystal formation of EFV-FA. It demonstrates that solubility of cocrystal form is as result of molecular transformation by non-covalent interaction in the crystalline material.

\subsection{Powder Dissolution Study}

Powder dissolution study of API-EFV and Cocrystal of EFV with FA shows a clear improvement of cocrystal formation.

\section{CONCLUSIONS}

Cocrystals of EFV-FA were obtained by neat grinding approach of green synthesis. The new cocrystal of EFV with FA shows improved pharmaceutical characteristics particularly, micromeritic flow properties, solubility and dissolution against unprocessed EFV. The prepared cocrystals were confirmed by FTIR spectroscopy, DSC and PXRD. The vibrational spectroscopy-FTIR, revealed the possible halogen bonding interactions between EFV and EFV-FA cocrystals could be formulated in an immediate release dosage form to attain a rapid and complete release of the API available for absorption overcoming problem of low solubility of drug which can be explored to industrial scale.

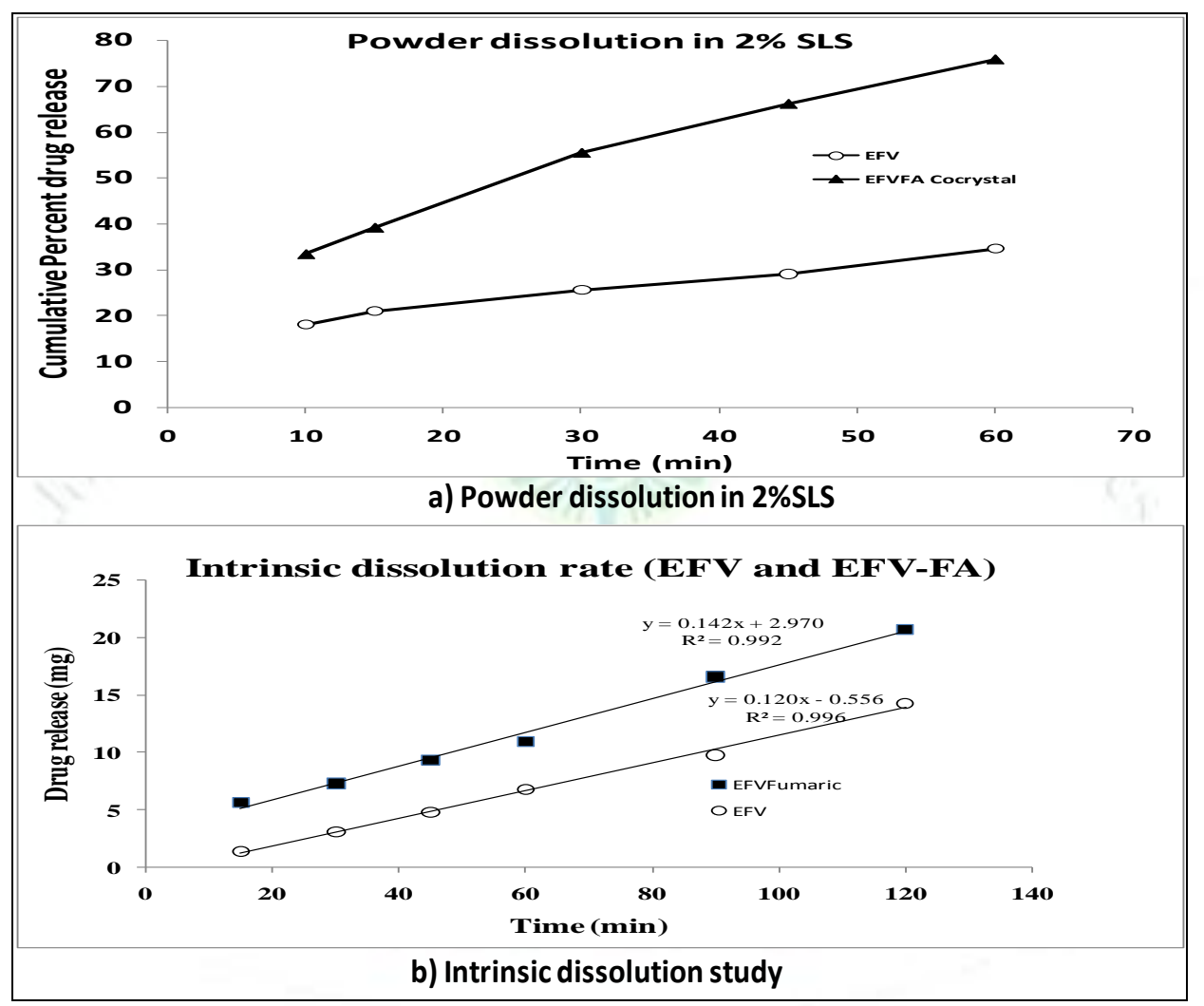

Figure 4 a) Powder dissolution study in $2 \%$ SLS b) intrinsic dissolution study of EFV and EFV-FA cocrystals

Only $34.52( \pm 1.22 \%)$ EFV was released from API powder in comparison with $75.70( \pm 0.66 \%)$ from cocrystal powder at the end of $60 \mathrm{~min}$ in powder dissolution study (Fig.4a). The obvious improvement in dissolution characteristics of cocrystal can be correlated to intermolecular interactions between EFV and FA.

The IDR of EFV was $126.38 \pm 18.51 \mu \mathrm{g} / \mathrm{min} / \mathrm{cm}^{2}$ while that EFV-FA cocrystal was $148.78 \pm 10.58 \mu \mathrm{g} / \mathrm{min} / \mathrm{cm}^{2}$ as determined from the slope of dissolution curve (Fig. 4b). EFV dissolved more rapidly from the cocrystal tablet formulation that API tablets, consistent with the solubility studies outcomes.

\section{Conflict of Interest}

The authors declare that they have no conflict of interest.

\section{Acknowledgements}

Authors are thankful to Director, School of Pharmacy, S.R.T.M. University, Nanded and Director, RUSACentre for Advanced Sensor Technology, Dr B.A.M. University, Aurangabad for providing required facility and we are also grateful to Mylan Laboratories, Hyderabad for providing gift sample of EFV. 


\section{REFERENCES}

1. Desiraju GR. Chemical crystallography and crystal engineering. Chem Crystallogr Cryst Eng. International Union of Crystallography; 2014; 1:380-1.

2. U.S. Department of Health and Human Services, Food and Drug Administration Center for Drug Evaluation and Research (CDER) Guidance for Industry Regulatory Classification of Pharmaceutical Co-Crystals. 2013.

3. Savjani JK. Co - crystallization: An approach to improve the performance characteristics of active. Asian J Pharm. 2015; (July-September):147-51

4. Bysouth SR, Bis JA, Igo D. Cocrystallization via planetary milling: Enhancing throughput of solid-state screening methods. Int J Pharm [Internet]. Elsevier B.V.; 2011; 411(12):169-71. Available from: http://dx.doi.org/10.1016/j.ijpharm.2011.03.037

5. Apshingekar PP, Aher S, Kelly AL, Brown EC, Paradkar A. Synthesis of Caffeine / Maleic Acid Co-crystal by Ultrasoundassisted. J Pharm Sci [Internet]. Elsevier Ltd; 2016; 106(1):66-70. Available from: http://dx.doi.org/10.1016/j.xphs.2016.09.009

6. Trask A V, Samuel WD, Jones W. Solvent-drop grinding green polymorph control of cocrystallisation. Chem Commun. 2004; 2004:890-1.

7. Duarte I, Andrade R. Green production of cocrystals using a new solvent-free approach by spray congealing. Int J Pharm 2016; http://dx.doi.org/10.1016/j.ijpharm.2016.04.010

8. Berry DJ, Steed JW. Pharmaceutical cocrystals, salts and multicomponent systems; intermolecular interactions and property based design. Adv Drug Deliv Rev J. 2017

9. Chadha R, Arora P, Saini A, Jain DS. An Insight into Thermodynamic Relationship Between Polymorphic Forms of Efavirenz. J Pharm Pharm Sci. 2012; 15(2):234-51.

10. Fandaruff C, Rauber GS, Andrea M. Araya-Sibaja RNP, Carlos EM de Campos HVR, Monti GA, Malaspina T, et al. Polymorphism of Anti-HIV Drug Efavirenz : Investigations on Thermodynamic and Dissolution Properties Polymorphism of Anti-HIV Drug Efavirenz: Investigations on Thermodynamic and Dissolution Properties. Cryst Growth Des. 2014; (14):4968-497.

11. Zaini E, Wahyu D, Octavia M, L Fitriani. Influence of Milling Process on Efavirenz Solubility. J Pharm Bioall Sci. 2017; 9:22-5.

12. Koh PT, Chuah JN, Talekar M, Gorajana A, Garg S. Formulation Development and Dissolution Rate Enhancement of Efavirenz by Solid Dispersion Systems. Indian J Pharm Sci. 2013; 75(3):291-301.

13. Rajurkar VG, Nagare AS, Vilas G. Tablet Formulation and Enhancement of Aqueous Solubility of Efavirenz by Solvent Evaporation Co-Crystal Technique. Med Chem (Los Angeles). 2015; S2:2.

14. Perlovich GL, Volkova T V, Bauer-brandl A. Towards an Understanding of the Molecular Mechanism of Solvation of Drug Molecules: A Thermodynamic Approach by Crystal Lattice Energy, Sublimation, and Solubility Exemplified by Paracetamol, Acetanilide , and Phenacetin. J Pharm Sci. 2006; 95(10):2158-69.

15. Pawar J, Amin PD. Development of efavirenz cocrystals from stoichiometric solutions by spray drying technology
Development of efavirenz cocrystals from stoichiometric solutions by spray drying technology. Mater Today Proc [Internet]. Elsevier Ltd; 2016; 3(6):1742-51. Available from: http://dx.doi.org/10.1016/j.matpr.2016.04.069

16. Mohammad MA, Alhalaweh A, Velaga SP. Hansen solubility parameter as a tool to predict cocrystal formation. Int J Pharm [Internet]. Elsevier B.V.; 2011; 407(1-2):63-71. Available from: http://dx.doi.org/10.1016/j.ijpharm.2011.01.030

17. Gadade DD, Pekamwar SS, Lahoti SR, Patni SD, Sarode MC. Cocrystallization of Etodolac: Prediction of Cocrystallization, Synthesis, Solid State Characterization And In Vitro Drug Release. Marmara Pharm J. 2017; 21(1):78-88

18. Gadade D, Kulkarni D, Rathi P, Pekamwar S, Joshi S. Solubility Enhancement of Lornoxicam by Crystal Engineering. Indian J Pharm Sci. 2017; 79(March):277-86.

19. Panzade P, Shendarkar G, Shaikh S, Rathi PB. Pharmaceutical Cocrystal of Piroxicam: Design, Formulation and Evaluation. Advanced pharmaceutical bulletin. 2017; 7(3):399-408.

20. Shewale S, Shete AS, Doijad RC, Kadam SS, Patil VA, Yadav A V. Formulation and Solid State Characterization of Nicotinamide-based Co- crystals of Fenofibrate. Indian J Pharm Sci. 2015; 77(3):328-34.

21. Carvalho PS jr, Almeida LR, Neto JHA, Medina ACQD, Menezes ACS. Structural and Theoretical Investigation of Anhydrous 3 , 4 , 5- Triacetoxybenzoic Acid. PLoS One. 2016; 11(6):1-12.

22. Aithal K, Pai A, Girish Pai A, Sathyanarayana MB. Preparation, Solid State Characterization of Etraverine CoCrystals with Improved Solubility Preparation, Solid State Characterization of Etraverine. Lat Am J Pharm. 2017; 36(5):972-9.

23. Hoguchi TK, A. C. PHASE-SOLUBILITY TECHNIQUES. Adv Chem Intrumentation. 1965; 4:212-7.

24. Grossjohann C, Eccles KS, Maguire AR, Lawrence SE, Tajber L, Corrigan OI, et al. Characterisation, solubility and intrinsic dissolution behaviour of benzamide: Dibenzyl sulfoxide cocrystal. Int J Pharm [Internet]. Elsevier B.V.; 2012; 422(12):24-32. Available from: http://dx.doi.org/10.1016/j.ijpharm.2011.10.016

25. Greenhalgh DJ, Williams AC, Timmins P, York P. Solubility parameters as predictors of miscibility in solid dispersions. $\mathrm{J}$ Pharm Sci. 1999; 88(11):1182-90.

26. Pharmacopeia US. United State Pharmacopoeia 29-National Formulary-24. 2006th ed. United State Pharmacopoeia 29National Formulary-24. Rockville: United States Pharmacopeial Convention; 2006. 3017 p.

27. Larkin P. Infrared and Raman Spectroscopy. Elsevier. 2011. 73-115 p.

28. Alves L, Soares M, de Albuquerque C, da Silva É, Vieira A, Fontes D, et al. Solid dispersion of efavirenz in PVP K-30 by conventional solvent and kneading methods. Carbohydr Polym j. $2014 ; 104: 166-74$

29. El-gizawy SA, Osman MA, Arafa MF, Maghraby GM El. Aerosil as a novel co-crystal co-former for improving the dissolution rate of hydrochlorothiazide. Int J Pharm [Internet]. Elsevier B.V.; 2015; 478:773-8. Available from: http://dx.doi.org/10.1016/j.ijpharm.2014.12.037 